\title{
Optimasi Kolom Pemisahan di Kilang Propylene Pertamina RU IV Cilacap
}

\author{
Kristinah Haryani \\ Jurusan Teknik Kimia, Fakultas Teknik, Universitas Diponegoro \\ Jl. Prof. Soedarto, SH, Kampus Undip Tembalang, Semarang, Indonesia 50275 \\ Email:krisyani_83@yahoo.co.id
}

Diterima: 20-02-2020; Direvisi: 08-06-2020; Dipublikasi: 01-09-2020

\begin{abstract}
Abstrak
Distilasi merupakan salah satu proses terpenting dalam pengolahan minyak bumi. Propylene Recovery Unit (PRU) merupakan unit yang berfungsi untuk memisahkan dan mengolah LPG campuran (Propylene, Propane, Ethylene, Ethane, $n$-butane, methane, iso butane) dari Unit LPG Merox. Produk utama yang dihasilkan dari unit Propylene Recovery Unit ini adalah produk Propylene dan $L P G$. Feed pada unit PRU berupa produk $L P G$ campuran yang selanjutnya akan mengalami proses pemisahan pada kolom pemisahan Propane Propylene. Berdasarkan hasil evaluasi menggunakan simulasi dan analisa data diatas dapat disimpulkan bahwa jumlah teoritical tray berdasarkan umpan pada verifikasi data desain sudah sesuai dengan jumlah teoritical tray sebenarnya. Jumlah teoritical tray berdasarkan umpan pada bulan Mei dan Juni sudah sesuai dengan jumlah teoritical sebenarnya. Namun dengan nilai Refuks Ratio Minimum diatas batas maksimalnya. Pada optimasi Refluk Rate pada bulan Mei didapatkan hasil semakin tinggi nilai Refluks Rate maka jumlah yield Propylene nya akan naik sedangkan kemurnian nya akan menurun. Dan untuk optimasi Tekanan Kondenser didapatkan hasil bahwa semakin tinggi tekanan kondenser nya maka hasil yield Propylene juga akan semakin naik. Namun untuk kemurniannya, kenaikan tekanan kondenser tidak berpengaruh. Pada optimasi Refluk Rate pada bulan Juni didapatkan hasil semakin tinggi nilai Refluks Rate maka jumlah yield Propylene nya akan naik sedangkan untuk kemurnian nya akan menurun. Dan untuk optimasi Tekanan Kondenser didapatkan hasil bahwa semakin tinggi tekanan kondenser nya maka hasil yield Propylene dan purity Propane juga akan semakin naik.
\end{abstract}

Kata kunci: Distilasi; Propylene Recovery Unit; Jumlah tray

\section{Abstract}

Distillation is one of the most important processes in petroleum processing. Propylene Recovery Unit (PRU) is a unit that functions to separate and process mixed LPG (Propylene, Propane, Ethylene, Ethane, n-butane, methane, iso butane) from the Merox LPG Unit. The main products produced from the Propylene Recovery Unit are Propylene and LPG products. Feeds on the PRU unit in the form of a mixture of LPG products which will then undergo a process of separation in the Propane Propylene separation column. Based on the evaluation results using simulation and data analysis above, it can be concluded that the number of theoretical trays based on the feed in the verification of design data is in accordance with the actual theoretical tray counts. The theoretical tray counts based on feeds in May and June are in accordance with the actual theoretical counts. But with a Minimum Reflux Ratio above the maximum limit. In the optimization of the reflux rate in May, the results showed that the higher the reflux rate, the amount of Propylene yield will increase while the purity will decrease. And for the optimization of the Condenser Pressure, the results show that the higher the condenser pressure, the yield of Propylene will also increase. But for its purity, the condenser pressure increase has no effect. In the optimization of the Refluk Rate in June, the higher the value of the Reflux Rate will be, the amount of Propylene yield will rise while for purity it will decrease. And for the optimization of the Condenser Pressure, the results show that the higher the condenser pressure, the yield of Propylene and purity Propane will also increase.

Keywords: Distilation; Propylene Recovery Unit; Tray Number

\section{Pendahuluan}

Propylene Recovery Unit merupakan unit yang berfungsi untuk memisahkan dan mengolah LPG campuran dari Unit LPG(Liquified Petroleum Gas) Merox. Produk utama yang dihasilkan dari unit Propylene Recovery Unit ini adalah produk Propylene dan LPG. Umpan pada unit PRU berupa produk LPG campuran yang selanjutnya akan mengalami proses pemisahan pada kolom pemisahan $\mathrm{C} 3 / \mathrm{C} 4$. Pada kolom pemisahan $\mathrm{C} 3 / \mathrm{C} 4$, LPG campuran akan mengalami proses pemisahan menjadi produk C3 campuran di overhead dan C4 sebagai komponen blending LPG di kolom bawah [1]. Produk C3 campuran selanjutnya akan mengalami proses pemisahan di kolom pemisahan C3 menjadi produk Propylene 
dan Propane, dimana produk Propylene akan menjadi produk akhir dan disimpan ditangki penyimpanan Propylene, sementara Propane akan menjadi komponen blending C4 sebagai produk LPG sebelum disimpan di tangki penyimpanan LPG. Tray pada kolom pemisahan C3/C4 ini sangat dipengaruhi oleh pengaturan kondisi operasi pada kolom [2].

Pada PT. Pertamina RU IV Cilacap telah terjadi perubahan umpan yang masuk ke kolom pemisahan C3 dimana kapasitas umpan mengalami kenaikan dari $38.1 \mathrm{~m}^{3} / \mathrm{h}$ desain $\mathrm{ke} 50 \mathrm{~m}^{3} / \mathrm{h}$ aktual serta terjadinya perubahan komposisi Propane dan Propylene pada umpan. Dengan adanya perubahan umpan ini, perlu dilakukan evaluasi dan optimasi pada kolom pemisahan C3 agar proses pemisahan Propane dan Propylene pada kolom dapat tercapai sesuai dengan yield dan kemurnian yang diharapkan [3].

Tujuan dari optimasi ini adalah verifikasi kebutuhan tray teoritis kolom pemisahan C3 berdasarkan kondisi desain. Menentukan kebutuhan tray teoritis kolom pemisahan C3 pasca terjadinya perubahan umpan. Optimasi kolom pemisahan C3 variabel aliran reflux dan tekanan overhead pasca perubahan umpan untuk memperoleh proses pemisahan optimum [4].

Refluks pada distilasi merujuk pada produk cairan bagian atas dari kolom distilasi atau fraksionator yang berbalik kembali ke bagian atas kolom. Di dalam kolom, cairan refluks yang mengalir ke bawah memberikan pendinginan dan kondensasi uap yang mengalir ke atas sehingga meningkatkan efisiensi kolom distilasi. Semakin banyak refluks, semakin baik pemisahan kolom untuk bahan-bahan dengan titik didih rendah dari bahan-bahan bertitik didih yang lebih tinggi. Fungsi refluks, adalah memperbesar L/V di enriching section, sehingga mengurangi jumlah equibrium stage yang diperlukan untuk produc tquality yang ditentukan, atau, dengan jumlah stage yang sama, akan menghasilkan product quality yang lebih baik dengan mengandakan kontak kembali antara cairan dan uap agar panas yang digunakan efisien.

Kolom pemisahan $\mathrm{C} 3 / \mathrm{C} 4$ pada Unit Propylene Recovery berfungsi untuk memisahkan campuran $\mathrm{C} 3 \mathrm{mix}$ (Propane dan Propylene) dan C4 dari Unit LPG Merox. Kolom ini memiliki jumlah plate sebanyak 48. C4 akan keluar menjadi produk bawah dan akan dicampurkan dengan Propane dari kolom pemisahan C3 menjadi produk LPG. C3 campuran akan keluar dari tray ke-9 menjadi produk atas untuk selanjutnya diproses di kolom pemisahan C3 untuk memisahkan Propane dan Propylene [5].

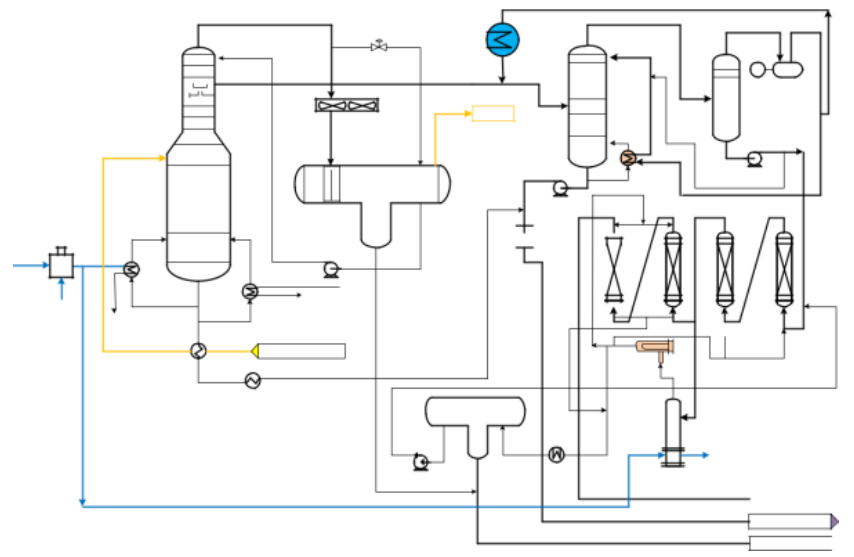

Gambar 1. Diagram Alir Proses Propylene Recovery Unit - Unit 104 [6]

Campuran C3/C4 dialirkan menuju kolom pemisahan C3/C4 untuk dipisahkan butane/butylene (C4) dan Propane/Propylene (C3) menggunakan sistem kolom distilasi konvensional. Lalu, aliran bawahnya (C4) digunakan untuk memanaskan umpan LPG dari Unit LPG Merox dengan Heat Exchanger sebelum memasuki kolom pemisahan C3/C4. Aliran C4 ini selanjutnya akan dicampur dengan aliran C3 (Propane) dari kolom pemisahan C3 menjadi LPG dengan spek yang sesuai dan akan dikirim ke tangki penyimpanan LPG. Campuran C3 yang merupakan produk atas 
dari kolom pemisahan $\mathrm{C} 3 / \mathrm{C} 4$ akan dialirkan ke peneriman kolom pemisahan $\mathrm{C} 3 / \mathrm{C} 4$ untuk memisahkan gas ethane dan senyawa yang lebih ringan (off-gas) dan akan direcycle ke Gas Concentration Section dari Unit Gas Concentration. Pada kondisi normal, tidak terdapat aliran off-gas pada aliran campuran C3 (Normally No Flow NNF).

Campuran C3 kemudian akan direflux kedalam kolom, dan keluar dari tray ke-9 berupa campuran Propane dan Propylene yang akan memasuki kolom pemisahan C3. Pada kolom pemisahan C3 ini, Propylene dan Propane dipisahkan dimana Propane akan keluar menjadi produk bawah dengan kemurnian minimal 99\% mol dan dicampurkan dengan aliran C4 dari kolom pemisahan C3/C4 menjadi LPG. Pemisahan Propylene-Propane sangat sulit, oleh karena itu untuk pemisahan dengan kolom distilasi biasa digunakan ratusan tray dan reflux rate yang sangat tinggi, serta 3 teknologi spesial berupa Heat Pump Compressor dan UOP High Flux Tube. Heat Pump Compressor digunakan sebagai pengganti condenser sehingga fraksinasi. Propylene dari Propane dapat dilakukan pada tekananrendah [7]. Overhead product dari kolom C3 akan masuk ke dalam Compressor Suction Drum, lalu dialirkan ke dalam Heat Pump Compressor, kemudian dialirkan ke C3 Splitter Reboiler, dan kembali kedalam kolom pemisahan C3. Overhead Product dari kolom pemisahan C3 ini dipanaskan dengan cara ditekan dan digunakan untuk memanaskan kembali produk bawah kolom tersebut. Setelah di dinginkan dan ditekan, keluaran overhead digabung dengan Propylene fasa liquid keluaran bagian bawah Compressor Suction Drum dan masuk kembali ke dalam kolom sebagai refluks untuk memastikan adanya reflux yang mencukupi pemisahan Propylene dan Propane. C3 Splitter Trim Condenser digunakan untuk menghilangkan sisa input panas dari Heat Pump Compressor terhadap aliran refluks Propylene yang akan masuk pemanas untuk menjaga kesetimbangan kalor pada kolom pemisahan C3 [8]. Sedikit aliran keluaran overhead vapor dari Heat Pump Compressor dialirkan ke Trim Condenser tersebut dimana aliran tersebut akan dikondensasi dan dikembalikan ke Compressor Suction Drum. Aliran ini dikontrol untuk menjaga tekanan pada Compressor Suction Drum, karena semakin banyak uap yang terkondensasi maka tekanannya akan menurun. Kolom distilasi yang diinginkan adalah kolom dengan tekanan rendah, karena pemisahan antara Propylene dan Propane efektif pada tekanan rendah.

Propylene fasa liquid dari Compressor Suction Drum merupakan Propylene yang telah dijenuhkan oleh air, maka Propylene ini akan dialirkan kedalam Propylene Driers (Molecular Sieve Driers) untuk menghilangkan kandungan airnya. Propylene yang sudah tidak mengandung air selanjutnya akan masuk Propylene Treaters (Activated Alumina Treaters) untuk menghilangkan kandungan logam Arsine, Phosphine, dan Antimony (serta logam lainnya). Propylene dengan kemurnian tinggi $(99.6 \%$ mol) akan dikirim ke dalam tangki penyimpanan.

\section{Metode Penelitian}

Pengumpulan data diperoleh dari data lapangan, berupa data kondisi operasi design, data kondisi operasi aktual di lapangan serta hasil analisa laboratoirum. Data aktual yang digunakan ialah data pada tanggal 2 Mei-25 Mei 2019 dan 2 Juni-25 Juni 2019.

Tabel 1. Data Design Hasil Analisa Komposisi Umpan Campuran C3

\begin{tabular}{ll}
\hline Senyawa & Komposisi (mol) \\
\hline $\mathrm{H} 2 \mathrm{O}$ & 0,1588 \\
Ethylene (C2H2 & 0,0004 \\
Ethane $(\mathrm{C} 2 \mathrm{H} 6)$ & 0,0724 \\
VinylBromide & 0,0149 \\
Propene & 430,8314 \\
\hline
\end{tabular}




\begin{tabular}{ll}
\hline Propane & 118,5329 \\
i-Butene & 118,5329 \\
1-Butene & 0,1786 \\
n-Butane (C4H10) & 0,0000 \\
i-Pentane & 0,0000 \\
\hline
\end{tabular}

\section{Pengolahan Data}

Perhitungan Jumlah Stage Ideal yaitu pertama menentukan komponen yang akan naik ke distilat. Menggunakan data tekanan aktual pada Condenser sebagai acuan. Menentukan temperatur yang akan menjadi trial awal Mencari Kvalue dengan pembacaan grafik literatur tiap komponen sesuai temperatur dan tekanan yang ditentukan Melakukan trial hingga tercapai hasil seperti persamaan dew-point berikut $=1$ Apabila jumlah tidak $=1$, maka dilakukan trial selanjutnya hingga jumlah $=1[9]$.

Simulasi dilakukan dengan langkah sebagai berikut menentukan component list dan fluid packages yang akan digunakan.Untuk fluid packages yang digunakan ialah Peng Robinson. Menyiapkan alat yang akan disimulasikan beserta data-data yang akan diperlukan untuk dioperasikan. Pada kali ini yang digunakan ialah kolom distilasi normal dengan Melakukan simulasi dengan mengoperasikan program simulasi menggunakan data primer sebagai kondisi awal [10]. Melakukan evaluasi pengaruh reflux rate dan tekanan condenser terhadap yield dan purity produk dengan melakukan variasi pada temperature dan tekanan condenser. Menentukan Komposisi yang akan masuk ke stream inlet dan refluks. Memasukkan parameter pada kolom distilasi berupa: Overhead produk rate, Bottom produk rate, Boilup ratio. Membuat Stream untuk Kondenser pada separator. Memilih separator pada kolom Pallete.

\section{Hasil dan Pembahasan}

Verifikasi data desain (Umpan dan Teoritical Tray). Melakukan simulasi dengan mengoperasikan program simulasi HYSYS menggunakan data primer sebagai kondisi awal [11]. Melakukan evaluasi pengaruh reflux rate dan tekanan condenser terhadap yield dan kemurnian produk dengan melakukan variasi pada temperature dan tekanan condenser. Menentukan Komposisi yang akan masuk ke aliran masuk dan refluks. Memasukkan parameter pada kolom distilasi berupa: Overhead produk rate, Bottom produk rate, Boilup ratio [12]. Membuat Stream untuk Kondenser pada separator. Memilih separator pada kolom Pallete. Verifikasi data desain (Umpan dan Teoritical Tray) jumlah tray 190 dan nilai Refluks Ratio Minimum sebesar 12,5. Berdasarkan hasil perhitungan manual diatas, dilakukan simulasi sehingga diperoleh data sebagai berikut:

Tabel 2. Hasil Perhitungan Data Design Komponen Distilat

\begin{tabular}{lllll}
\hline Komponen & $\mathrm{Y}$ & $\mathrm{K}$ & $\mathrm{X}=\mathrm{Y} / \mathrm{K}$ & $\mathrm{Alfa}=\mathrm{K} / \mathrm{K}$ HK \\
\hline Propylene $(\mathrm{LK})$ & 0,892 & 1,05 & 0,983 & 1,33 \\
Propane $(\mathrm{HK})$ & 0,1072 & 0,16 & 0,018 & 1 \\
TOTAL & & & 1,001 & \\
\hline
\end{tabular}

Tabel 3. Hasil Perhitungan Data Design Komponen Bottom

\begin{tabular}{lllll}
\hline Komponen & $\mathrm{Y}$ & $\mathrm{K}$ & $\mathrm{X}=\mathrm{Y} / \mathrm{K}$ & $\mathrm{Alfa}=\mathrm{K} / \mathrm{K}$ HK \\
\hline Propylene (LK) & 0,359 & 0,06 & 0,054 & 1,2 \\
Propane (HK) & 0,641 & 0,71 & 0,921 & 1 \\
TOTAL & & & 0,975 & \\
\hline
\end{tabular}

Berdasarkan perhitungan dari Tabel 2 dan 3 didapatkan hasil Heavy Key Component dan Light Key Component 
Penulis pertama dkk./Jurnal Rekayasa Mesin p-ISSN: 1411-6863, e-ISSN: 2540-7678 Vol.15|No.2|126-136|Agustus|2020

sebesar 0,0170 dan 0,0034 dengan jumlah tray 190 dan nilai Refluks Ratio Minimumsebesar 12,5. Berdasarkan hasil perhitungan manual diatas, dilakukan simulasi. Pada simulasi ini, digunakan metode steady state maka hanya memasukkan data masing masing stream yang berhubungan. Dengan simulasi tersebut, dengan memasukkan nilai Heavy Key Component dan Light Key Component seperti perhitungan maka didapat jumlah tray yang dibutuhkan sebanyak 191,308 dengan tekanan kondenser sebesar 12,1 atm, tekanan reboiler 13 atm, External Reflux Ratio 10,6, Minimum Refluk Ratio 9,803. Jumlah tray ini sudah sesuai dengan data aktual jumlah tray yang sebenarnya yaitu sejumlah 190 dan nilai Refluks Ratio Minimum dibawah batas maksimalnya [13].

\subsection{Evaluasi Tray Teoritis Terhadap Perubahan Jumlah Umpan pada Bulan Mei}

Pada data aktual di bulan Mei, umpan yang masuk ke kolom distilasi (dalam fraksi mol) lebih didominasi senyawa Propane yaitu 74,65 dan untuk jumlah Propylene nya sebanyak 25,206053.

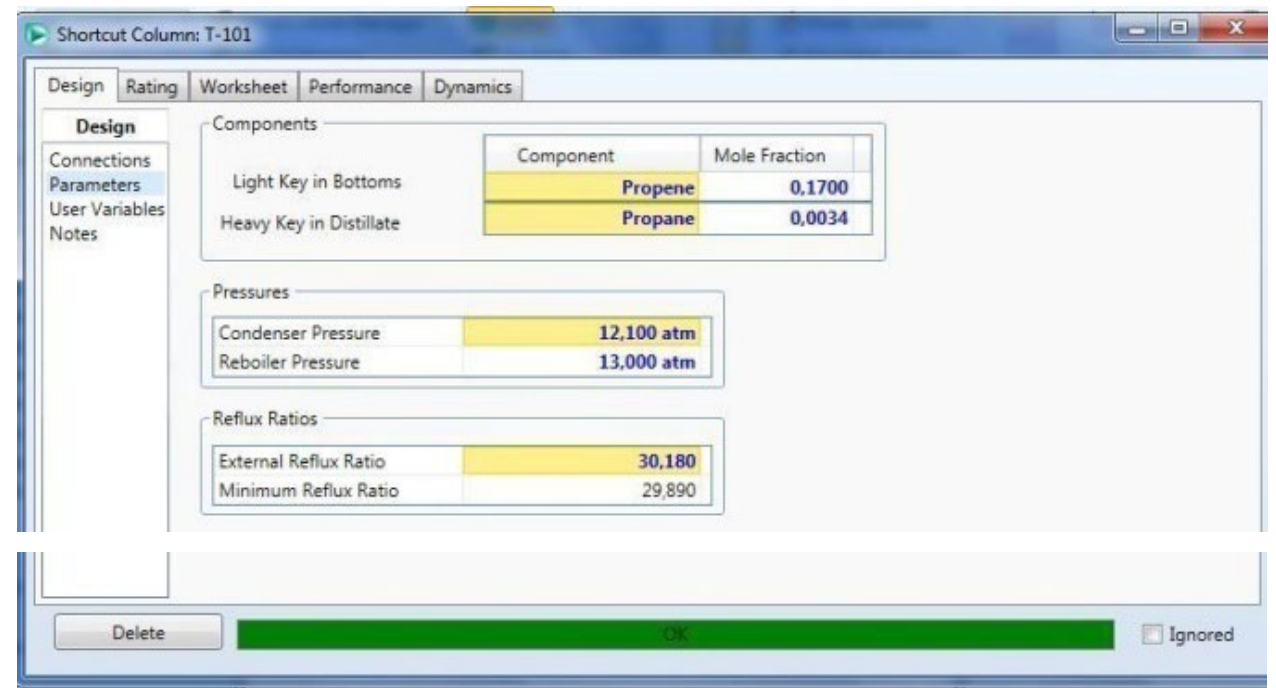

Gambar 2. Data Kondisi Operasi Aktual Bulan Mei

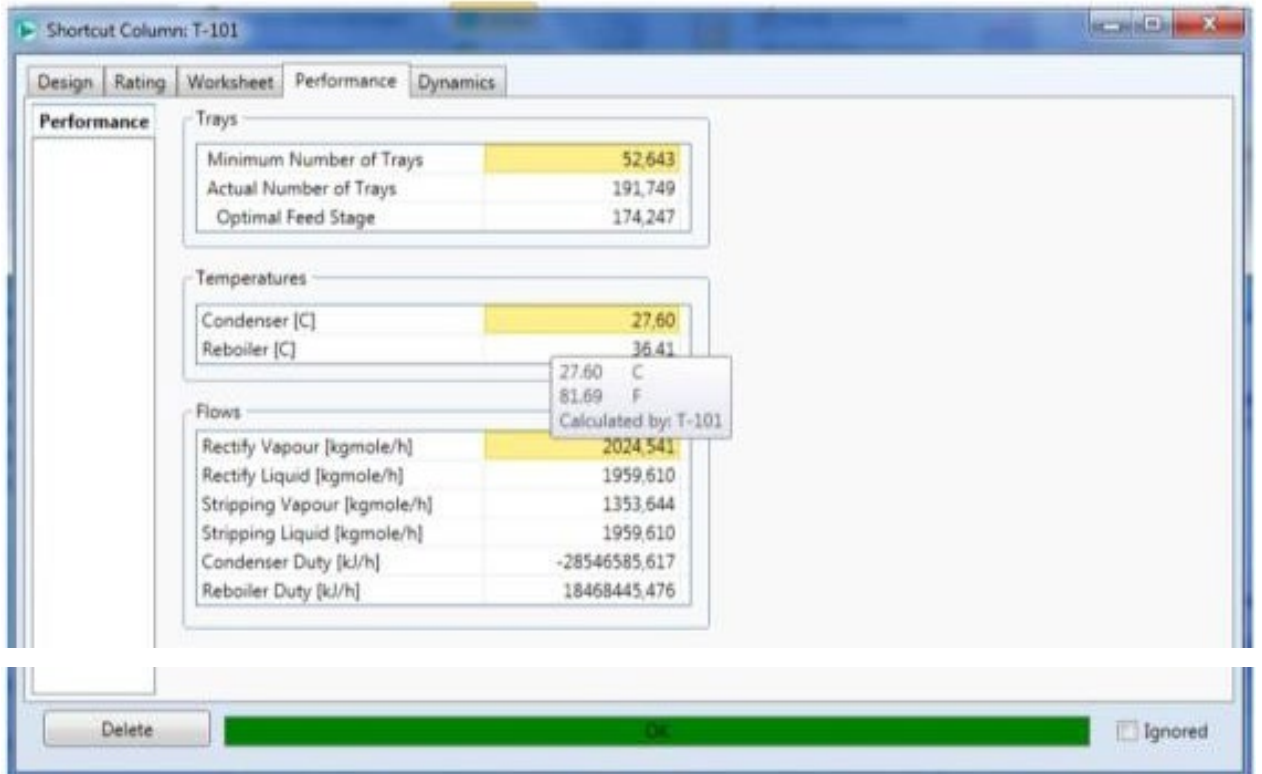

Gambar 3. Hasil Aktual Tray Bulan Mei 
Berdasarkan Gambar 3 dapat disimpulkan bahwa jumlah tray yang dibutuhkan dengan menyesuaikan komposisi Light Key Component, Heavy Key Component dan umpan pada bulan Mei maka jumlah tray sudah sesuai dengan jumlah tray hasil data design. Namun dengan nilai Refuks Ratio Minimum diatas batas maksimalnya. Hal ini disebabkan karena semakin tinggi Reflux Rate, maka semakin tinggi kontak antara stream liquid dari reflux yang relatif murni dengan vapor yang menuju ke atas kolom distilasi [14]. Dengan kontak yang lebih banyak, maka fraksi ringan yang terbawa oleh vapor akan semakin banyak sehingga distilat yang diperoleh akan lebih banyak menganduk fraksi ringan, yakni Propane \&Propylene. Hal inilah yang membuat produk distilat menjadi semakin murni. Sehingga tray yang dibutuhkan juga akan semakin bertambah banyak dan beroperasi menggunakan refluks ratio minimum diatas batas maksimal juga untuk pemurnian yang optimum.

\subsection{Evaluasi Tray Teoritis Terhadap Perubahan Jumlah Umpan pada Bulan Juni}

Pada data aktual di bulan Juni, umpan yang masuk ke kolom distilasi (dalam fraksi mol) lebih didominasi senyawa propene yaitu 56,20 dan untuk jumlah Propylene nya sebanyak 43,76. Maka dapat disimpulkan bahwa jumlah tray yang dibutuhkan dengan menyesuaikan komposisi Light Key Componen, Heavy Key Componen dan umpan pada bulan Juni, maka jumlah tray tersebut sudah sesuai dengan jumlah tray hasil data design [15].

Namun dengan menggunakan Refluks Ratio Minimum dengan batas maksimum yang ditentukan. Hal ini disebabkan karena semakin tinggi Reflux Rate, maka semakin tinggi kontak antara stream liquid dari reflux yang relatif murni dengan vapor yang menuju ke atas kolom distilasi [16]. Dengan kontak yang lebih banyak, maka fraksi ringan yang terbawa oleh vapor akan semakin banyak sehingga distilat yang diperoleh akan lebih banyak menganduk fraksi ringan, yakni Propane \& Propylene. Hal inilah yang membuat produk distilat menjadi semakin murni. Sehingga untuk mendapatkan kemurnian yang optimum digunakan Refluk Ratio Minimum sebesar 13,805.

\subsection{Optimasi Kondisi Kolom pada Bulan Mei}

Untuk memenuhi jumlah tray sesuai data desain dan beroperasi dengan Refluks Ratio Minimum yang dibawah batas maksimum yang ditentukan maka dilakukan optimasi dengan pengaturan kondisi operasi. Optimasi kondisi operasi yang di variasikan adalah tekanan condenser dan Refluks Rate [17].

\subsection{Optimasi Refluks Rate}

Pada optimasi ini dilakukan variasi Refluks Rate dengan low bound sebesar 610, high bound sebesar 800 dan step size nya 10. Nilai ini didasarkan dengan kondisi operasi aktual masing masing kolom.

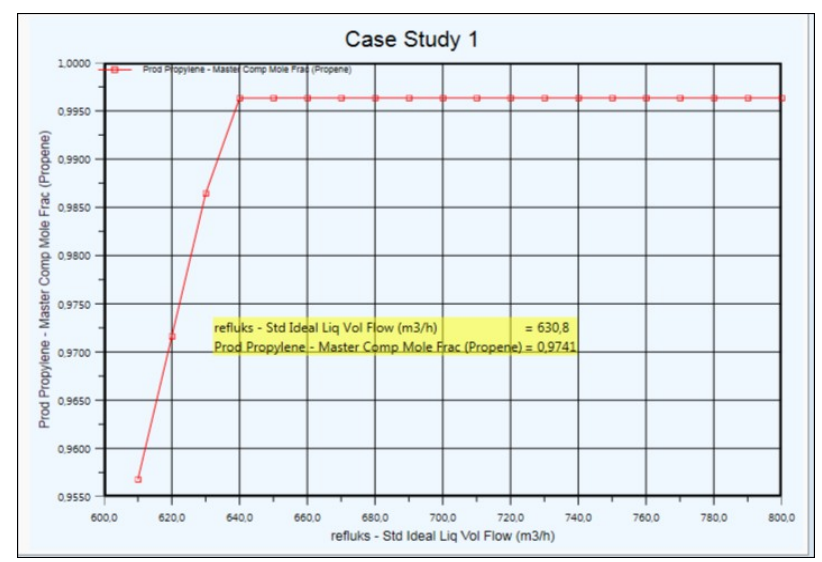


Gambar 4. Grafik Optimasi Refluk Rate vs \% kemurnian

Propylene yang Dihasilkan Bulan Mei

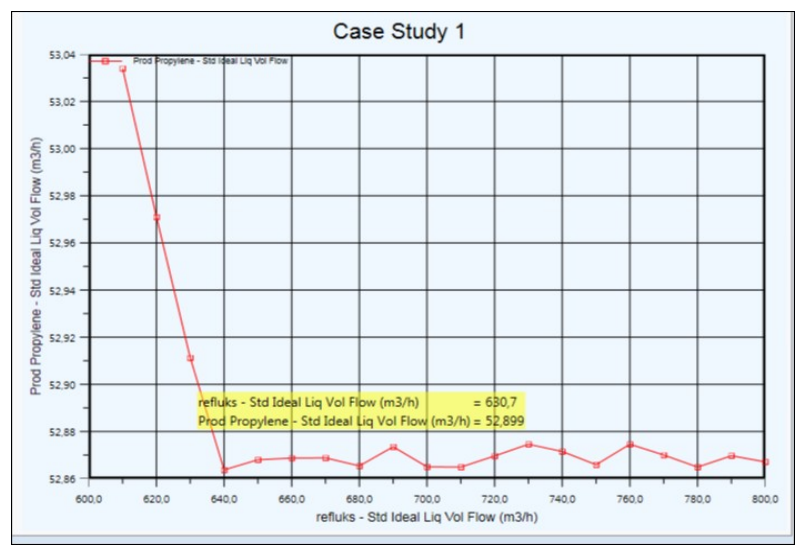

Gambar 5. Grafik Optimasi Refluk Rate vs Yield

Propylene yang Dihasilkan Bulan Mei

Berdasarkan pada Gambar 4 dan Gambar 5 maka dapat disimpulkan bahwa semakin tinggi nilai Refluks Rationya maka purity nya juga akan semakin naik dan mencapai titik optimum sesuai spec pada saat Refluks Ratio 64,0 yaitu sebesar 99,5\%. Sehingga nilai yield akan konstan seiring dengan kenaikan nilai Refluks Rate. Namun, berkebalikan dengan hasil purity. pada saat Refluks Ratio mencapai titik optimum yang sama, maka hasil yieldnya akan turun pada nilai 52,87. Hal ini disebabkan karena semakin tinggi Reflux Rate, maka semakin tinggi kontak antara stream liquid dari reflux yang relatif murni dengan vapor yang menuju ke atas kolom distilasi [14]. Dengan kontak yang lebih banyak, maka fraksi ringan yang terbawa oleh uap akan semakin banyak sehingga distilat yang diperoleh akan lebih banyak menganduk fraksi ringan, yakni Propane \&Propylene. Hal inilah yang membuat produk distilat menjadi semakin murni.

\subsection{Optimasi Tekanan Kondenser}

Pada optimasi ini dilakukan variasi tekanan kondenser dengan low bound sebesar 11,71 atm, high bound sebesar 12,49 atm dan step size nya 49,03 atm.

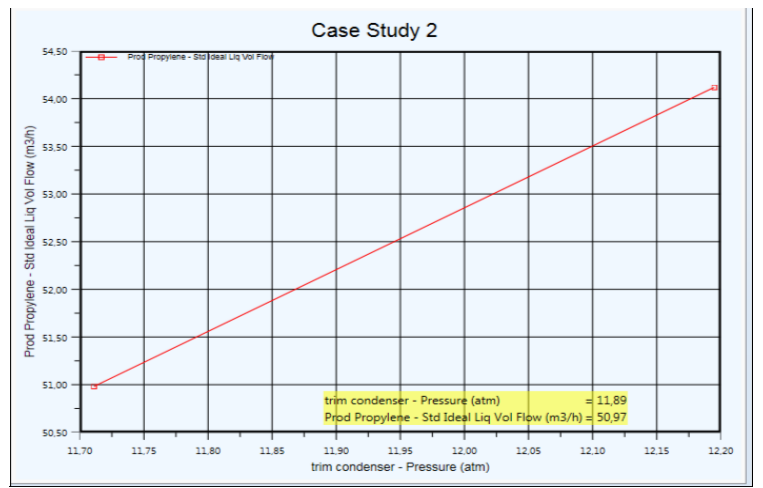

Gambar 6. Grafik Optimasi Tekanan Kondenser vs Yield Propylene yang Dihasilkan Bulan Mei 


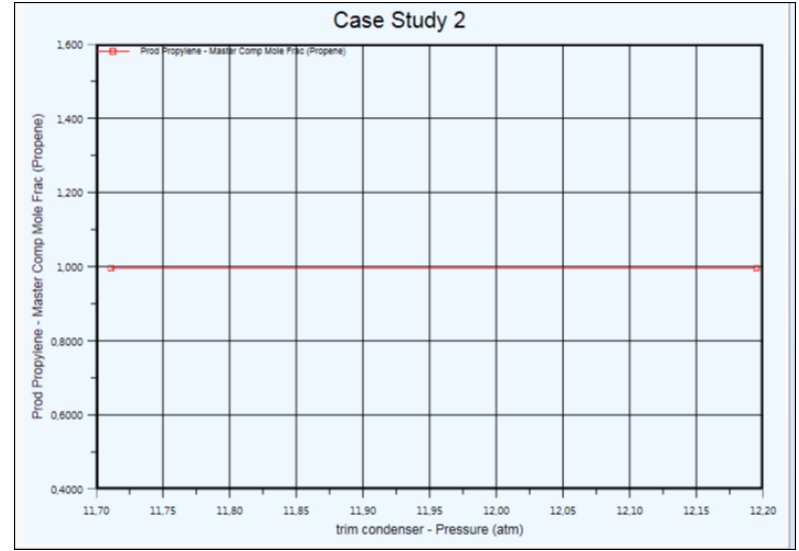

Gambar 7. Grafik Optimasi Tekanan Kondenser vs \% Purity

Propylene yang Dihasilkan Bulan Mei

Untuk optimasi tekanan kondenser, berdasarkan Gambar 6 dan 7 dapat disimpulkan bahwa semakin tinggi tekanan kondenser nya maka hasil yield Propylene juga akan semakin naik. Untuk optimasi tekanan kondenser pada kemurnian dapat dilakukan pada tekanan 12,2 dengan hasil yield nya mencapai $54,2 \mathrm{~m} / \mathrm{h}$. Namun untuk kemurniannya, kenaikan tekanan kondenser tidak berpengaruh. Hal ini disebabkan karena dengan naiknya tekanan pada kondenser maka perbedaan tekanan pada puncak dan bottom kolom semakin besar. Besarnya tekanan akan menyebabkan kenaikan suhu, yang menyebabkan penguapan fraksi berat akan lebih banyak. Sehingga pada produk atas, jumlah fraksi ringan akan berkurang dalam satuan persen mol sehingga menyebabkan kemurnian pada produk menurun [18]. Pada variasi tekanan kondenser dengan low bound sebesar 11,71 atm, high bound sebesar 12,49 atm dan step size nya 49,03 atm.

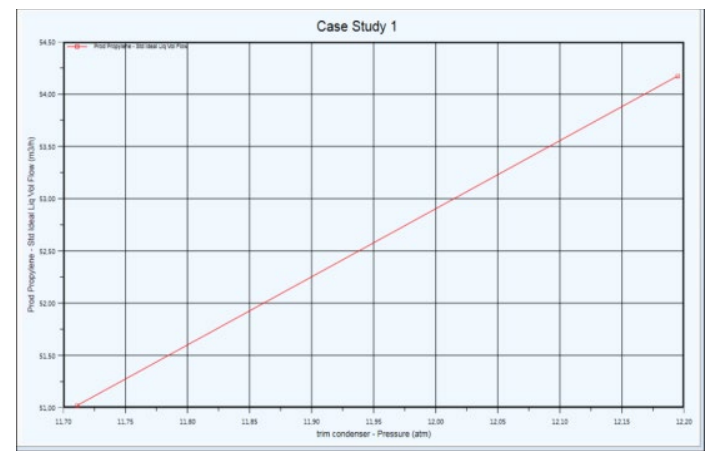

Gambar 8. Grafik Optimasi Tekanan Kondenser vs \% Yield Propylene yang Dihasilkan Bulan Juni

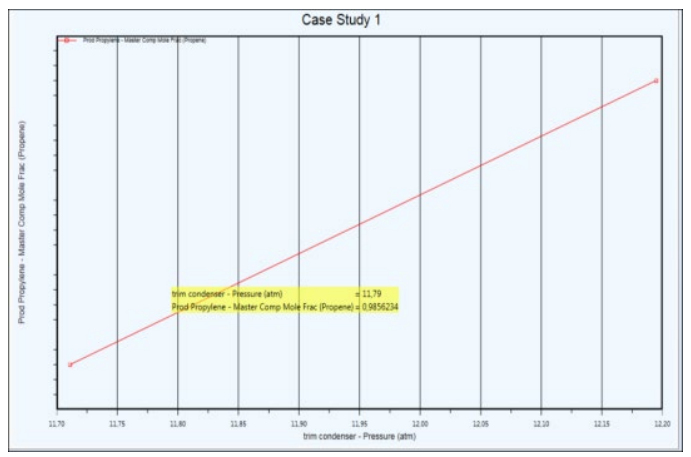


Gambar 9. Grafik Optimasi Tekanan Kondenser vs \% Purity

Propylene yang Dihasilkan Bulan Juni

Untuk optimasi tekanan kondenser, berdasarkan Gambar 8 dan 9 dapat disimpulkan bahwa semakin tinggi tekanan kondensernya maka hasil yield dan purity Propylene juga akan semakin naik. Untuk optimasi tekanan kondenser pada purity dapat dilakukan pada tekanan 12,2 atm dengan hasil yield nya mencapai 54,15 m³ $/ \mathrm{h}$. Hal ini disebabkan karena dengan naiknya tekanan pada kondenser maka perbedaan tekanan pada puncak dan bottom kolom semakin besar. Besarnya tekanan akan menyebabkan kenaikan suhu, yang menyebabkan penguapan fraksi berat akan lebih banyak. Sehingga pada produk atas, jumlah fraksi ringan akan berkurang dalam satuan persen mol sehingga menyebabkan purity pada produk juga akan ikut naik [19].

\subsection{Optimasi Kondisi Kolom pada Bulan Juni}

Untuk memenuhi jumlah tray sesuai data desain dan beroperasi dengan Refluks Ratio Minimum yang dibawah batas maksimum yang ditentukan maka dilakukan optimasi dengan pengaturan kondisi operasi. Optimasi kondisi operasi yang di variasikan adalah tekanan kondenser, Refluks Rate

\subsubsection{Optimasi Refluks Rate}

Pada optimasi ini dilakukan variasi Refluks Rate dengan low bound sebesar 610, high bound sebesar 800 dan step size nya 10. Nilai ini didasarkan dengan kondisi operasi aktual masing masing kolom.

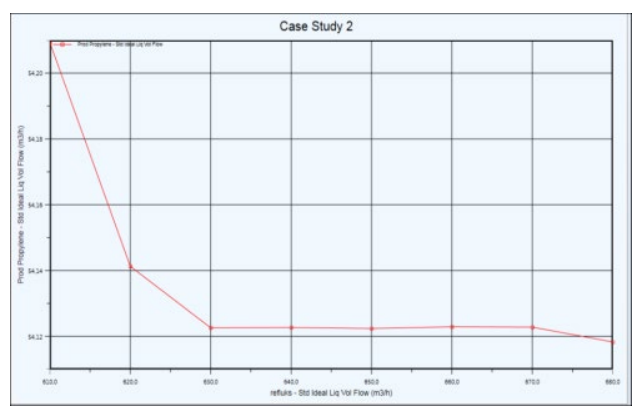

Gambar 10. Grafik Optimasi Refluks Rate vs \% yield

Propylene yang Dihasilkan Bulan Juni

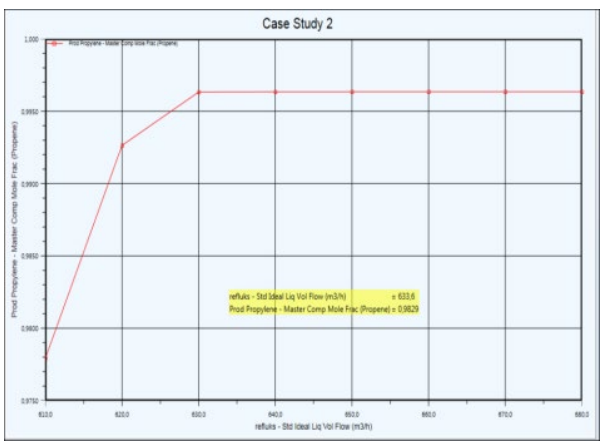

Gambar 11. Grafik Optimasi Refluks Rate vs \% Purity

Propylene yang Dihasilkan Bulan Juni

Berdasarkan pada Gambar 10 dan Gambar 11 maka dapat disimpulkan bahwa semakin tinggi nilai Refluks 
Rationya maka purity nya juga akan semakin naik dan mencapai titik optimum sesuai spesifikasi pada saat Refluks Ratio 630 yaitu sebesar 99,56\%. Sehingga nilai yield akan konstan seiring dengan kenaikan nilai Refluks Rate. Namun, berkebalikan dengan kemurniannya. Pada saat Refluks Ratio mencapai titik optimum yang sama, maka hasil yieldnya akan turun pada nilai 54,12 m³ h. Hal ini disebabkan karena semakin tinggi Reflux Rate, maka semakin tinggi kontak antara stream liquid dari reflux yang relatif murni dengan vapor yang menuju ke atas kolom distilasi [14]. Dengan kontak yang lebih banyak, maka fraksi ringan yang terbawa oleh vapor akan semakin banyak sehingga distilat yang diperoleh akan lebih banyak menganduk fraksi ringan, yakni Propane \&Propylene. Hal inilah yang membuat produk distilat menjadi semakin murni [15].

\section{Kesimpulan}

Berdasarkan hasil evaluasi menggunakan simulasi dan analisa data diatas dapat disimpulkan bahwa jumlah teoritical tray berdasarkan umpan pada verifikasi data desain sudah sesuai dengan jumlah teoritical tray sebenarnya. Jumlah teoritical tray berdasarkan umpan pada bulan Mei dan Juni sudah sesuai dengan jumlah teoritical sebenarnya. Namun dengan nilai Refuks Ratio Minimum diatas batas maksimalnya. Pada optimasi Refluk Rate pada bulan Mei didapatkan hasil semakin tinggi nilai Refluks Rate maka jumlah yield nya akan naik sedangkan untuk kemurnian nya akan menurun. Dan untuk optimasi Tekanan Kondenser didapatkan hasil bahwa semakin tinggi tekanan kondenser nya maka hasil yield Propylene juga akan semakin naik. Namun untuk kemurniannya, kenaikan tekanan kondenser tidak berpengaruh. Pada optimasi Refluk Rate pada bulan Juni didapatkan hasil semakin tinggi nilai Refluks Rate maka jumlah yield nya akan naik sedangkan untuk jumlah purity nya akan menurun. Dan untuk optimasi Tekanan Kondenser didapatkan hasil bahwa semakin tinggi tekanan kondenser nya maka hasil yield dan purity Propylene juga akan semakin naik.

\section{Daftar Pustaka}

[1] Maté, V.I.A., Torrellas, S.A., Larriba, M., Separation of the Propane Propylene mixture with high recovery by a dual PSA process José Antonio Delgado Dobladez, Computers \& Chemical Engineering. 2020, 136, pp.1-11.

[2] Mauhar, S.M., Barjaktarovic, B.G., Sovilj, M.N., Optimization of Propylene-Propane distillation process. Chem. Pap. 2004,58, pp.386-390.

[3] Jiang, Z., Agrawal, R., Process intensification in multicomponent distillation: A review of recent advancements, Chem. Eng. Res. Des. 2019, 1, 47, pp.122-145.

[4] Kister, H.Z., Distillation Design, McGraw-Hill, New York, 1992.

[5] Noriler, D., Meier, H.F., Barros, A.A., Macel, M.R.W., Prediction of efficiencies through simultaneous momentum, mass and energy transfer analyses in a distillation sieve tray by CFD techniques, Computer Aided Chem. Eng. (2009) 27, pp. 1167-1172.

[6] PT. Pertamina (Persero) RU 3 Cilacap

[7] Christopher, C.C.E., Dutta, A., Farooq, S., Karimi, I.A., Process synthesis and optimization of Propylene/Propane separation using vapor recompression and self- -heat recuperation. Ind. Eng. Chem. Res. 2017, 56, pp.14557-14564.

[8] Kuah, W.C., Effendy, S., Farooq, S., Industrial scale Propylene/Propane separation using pressure vacuum swing adsorption. Ind. Eng. Chem. Res. 2018, 57, pp. 6451-6463.

[9] Fischer, C., Quarini, G., Three-dimensional heterogeneous modeling of distillation tray hydraulics, AIChE 
Annual Meeting.1998, pp. 15-20.

[10] Wang, X.L., Liu, C.J., Yuan, X.G., Yu, K., Computational fluid dynamics simulation of three-dimensional liquid flow and mass transfer on distillation column trays, Ind. Eng. Chem. Res. 2004 ,43,pp. 2556-2567.

[11] Ingham, J., Dunn, I.J., Heinzle, E., Prenosil, J.E., Snape, J.B.,. Chemical Engineering Dynamics: An Introduction to Modelling and Computer Simulation, third ed Wiley-VCH, Weinheim. 2007.

[12] Sun, Z., Yu, K., Yuan, X., Liu, C., A modified model of computational mass transfer for distillation column, Chem. Eng. Sci. 2007, 62, pp. 1839-1850.

[13] Li, X.G., Liu, D.X., Xu, S.M., Li, H., CFD simulation of hydrodynamics of valve tray, Chem. Eng. Process. Process Intensif. 2009, 48, pp.145-151.

[14] Rahmawati. Optimasi Tekanan dan Rasio Refluks pada Distilasi Fraksinasi Vakum terhadap Mutu Eugenol dari Minyak Daun Cengkeh (Eugenia caryophyllata). Jakarta: Universitas Sahid. 2014.

[15] Boronyák, I., Gyökhegyi, L., Mathematical efficiency evaluation of modern sieve trays, Chem. Eng. Technol. 2000,23,pp 584-586.

[16] Alizadehdakhel, A., Rahimi, M., Alsairafi A.A, CFD and experimental studies on the effect of valve weight on performance of a valve tray colu mn, Comput. Chem. Eng. 2010,34 pp 1-8.

[17] Mustofa, H.A., Direct calculation of number of actual plates,Chemical Engineering Science. 1974 vol 29,pp1997-1999.

[18] Lianghua,W., Juejian, C., Kejian,Y., Numerical simulation and analysis of gas flow field in serrated valve column, Chin. J. Chem. Eng. 2008, 16, pp 541-546.

[19] Bequette, B.W., Process Control; Modeling, Design and Simulation, Prentice Hall,.2003 , p. 374. 